\title{
Current Status and Expectation of Salt Containing Waste Water Discharged from Oil Production and Its Treatment
}

\author{
Wang Lisheng \\ School of Chemical Engineering and the Environment, Beijing Institute of Technology, Beijing, China
}

\section{Email address:}

lishengwang@bit.edu.cn

\section{To cite this article:}

Wang Lisheng. Current Status and Expectation of Salt Containing Waste Water Discharged from Oil Production and Its Treatment. Science Discovery. Vol. 4, No. 4, 2016, pp. 264-269. doi: 10.11648/j.sd.20160404.21

Received: June 24, 2016; Accepted: July 13, 2016; Published: August 8, 2016

\begin{abstract}
In this paper, we review the current status about the salt containing waste water discharged from oil production. Currently, most of the waste water discharged from oil production in China has not been treated by desalination. Soilsalinization has been an important environment problem. The salt-containing composition and mineralization degree data of reservoir water in major oil and gas fields of China were summarized. It can be seen that the reported data show very different and complex distribution of salt-containing composition of reservoir water. The application of computer simulation canimprove the prediction of the analytical data. The predicted data of water and salt concentration in the soil can be used to determine the boundary condition and initial condition of the simulation, and the limit of the sampling can be thus avoided. The results of the study will provide a scientific basis for environmental protection to build the standards of the salt contents of waste water and to prevent secondary salinization of soil of oil fields.
\end{abstract}

Keywords: Salt-Containing Waste Water from Oil Production, Pollution, Treatment

\section{油田含盐采油废水排放与治理的现状与展望}

\section{王利生}

化工与环境学院, 北京理工大学, 北京, 中国

\section{邮箱}

lishengwang@bit.edu.cn

摘要: 本文调研了国外和我国的高含盐油田采出水的污染问题及其治理的研究现状。文中的资料引用了西方发达国家 对油田采出水进行脱盐处理以保护环境的现状与对策。我国对于这个问题也很重视, 但在公开文献中尚未见到关于对 含盐采油废水进行工业化脱盐处理的报道。关于油田含盐废水排放对环境的危害, 特别是导致矿区土地盐渍化的问题, 在我国的公开文献中也未见报道。关于高含盐废水渠的排放导致两侧土地盐渍化的研究方法, 提出可以借助于电子计 算机进行数值模拟, 在获得大量分析数据的基础上进行预报, 从而弥补单纯靠实地布点采样分析数据在时空范围上的 局限性。

关键词: 含盐采油废水, 污染, 治理 


\section{1. 引言}

石油开采主要经历三个阶段: 初期阶段是利用油藏的 天然压力开采石油, 称为一次采油, 其采收率为 $10 \%$ 左右; 第二阶段是为保持地层压力向油层中注水或蒸汽开采, 称 为二次采油, 采收率能达到 $35 \%$ 左右; 第三个阶段, 即三 次采油阶段, 在提高石油采收率的方法中我国目前主要采 用化学驱的方法, 向注入水中加入一定量的水溶性高分子 聚合物（如聚丙烯酰胺）增加水相粘度, 同时降低水相渗 透率, 改善油水的流度比, 以提高原油采收率。目前, 我 国各大油田经过蒸气驱或水驱开采之后, 多数已进入中后 期。无论是二次采油或是三次采油, 由于地层中通常自然 存在大量的盐类，同时在地层中仍有大量的原油由于出水 严重而采收率不高, 注入的水就会在地层中形成高浓度的 含盐废水伴随原油一起被采出。在采油污水处理站目前的 的污水处理过程中（详见下节）, 尚未有对污水进行脱盐 的工艺, 国家的污水排放标准中也未有含盐量的排放标准, 这就导致了油田排放含盐采油废水的问题。近年来, 人们 发现含盐废水经排污渠的排放已经导致渠道两侧土地出 现了次生盐渍化等环境问题。开展高含盐采油废水排放及 其致矿区土地盐渍化的研究, 为油田高含盐废水排放标准 的建立和排放量控制提供依据具有重要意义。

\section{2. 高含盐采油废水处理及其致矿区土地盐渍化 的研究现状}

表1列出了我国各地典型油矿的储层盐水中主要离子 含量及矿化度 $[1-8]$ 。表1的数据显示我国各地油田地层水 盐含量和矿化度差别很大, 成份复杂, 所含盐类其阴离子 以氯离子和硫酸根离子为主, 阳离子则主要是钠、钾离子, 此外钙、镁离子的含量也比较高。地层水的矿化度以塔里 木盆地为最高, 其范围为 $22 \sim 320 \mathrm{~g} / \mathrm{L}$ 。由表 1 可见, 油田 采出水一般无机盐含量较高, 排放浓度从几万甚至能达到 几十万 $\mathrm{mg} / \mathrm{L}$ 。

以我国胜利油田现河采油厂为例, 该采油厂王家岗污 水站位于东营市东城区西南10km处, 1997年建成, 污水处 理工艺包括气浮、隔油、沉淀等物化工艺, 每天处理采出 水 2 万立方米, 其中 2 千立方米回注, 其余 1.8 万立方米外 排进入广浦沟, 径流约 $80 \mathrm{~km}$ 进入渤海 [9]。王家岗污水站 外排污水是典型的高含盐污水, 其水质检测数据列于表 $2[10]$ 。据报道, 胜利油田共有污水站 52 座, 目前每天实 际处理污水 70.4 万立方米 [11]。在该报道中指出, 我国油 田目前采用的采油污水处理技术均属于初级处理, 未进行 脱盐等深度处理, 这样大的高含盐废水排放量, 对于渤海 平原这样的易于发生风暴潮倒灌和地下海水入侵的生态 薄弱地区而言, 必然对环境产生巨大的影响, 其中首要的 生态危机问题就是排污渠两侧土地的次生盐渍化。据另文 报道 [12], 大庆油田在几十年的油气开发利用和油田建设 过程中, 使大庆及周边地区的地质环境遭受到了破坏, 产 生了七类十种, 包括土地沙化、草原退化和土壤盐碱化等 主要地质环境问题。这些地质环境问题, 长期以来未得到 足够重视, 目前已发展到相当严重的程度, 而且还在不断
加剧。大庆市及其周边地区的土地盐碱化面积已经达到 50.07 万 $\mathrm{hm}^{2}$ 。我国环渤海地区分布着我国的几个大油田, 包括辽河油田（盘锦）、冀东南堡油田（唐山）、大港油 田 (天津、河北)、胜利油田 (山东) 等, 这些近海的陆 上油田产生了大量含盐废水, 未经脱盐处理直接经渠道排 入渤海。由于环渤海地区地质环境本来就十分脆弱, 存在 严重的地下海水入侵、风暴潮致土地盐渍化等生态问题, 巨大数量的高含盐采油废水的排放给渤海湾湿地和渤海 水质都带来了生态灾难。从理论上分析, 高含盐采油废水 排放的过程可以从以下两个方面导致污水渠沿线土地的 次生盐渍化: (1)渗漏补给地下水致地下水位升高, 经地面 蒸散致土地盐渍化; (2)地下水性质是影响深层土壤盐分分 布的重要因素, 因此, 盐分从污水中直接经渗流扩散、水 盐运移过程进入地下含水层, 致地下水含盐量升高也是土 地盐渍化的主要因素。在互联网上能够获得的常规遥感数 据 (如LandsatTM等) 尚缺乏对地面的穿透能力。尽管我 们可以从植被的变化来推测和追溯土壤的盐渍化信息, 但 遥感数据与土壤水文地质数据尚不能达到相互准确配合。 面对这样的问题, 我们只有认真做好调查研究, 拿出可信 度高的分析测试数据使环保部门认识到问题的严重性, 并 提出解决问题的办法。

油田高含盐采出水的污染问题已经引起了世界各国 的重视。近年来, 加拿大和美国等国已经对采出水的各种 脱盐方法进行了系统研究 [13-20], 膜分离技术已经广泛 用于含油污水中乳化油、溶解油去除和脱盐的研究与工业 化生产, 发现纳滤和反渗透特别适用于脱盐。早在 1997 年, 美国在加利福尼亚州的SantaClarita进行了以反渗透 单元为核心的采油污水深度处理工艺中试。采油污水经核 桃壳过滤、澄清、生物滤池、压滤、离子交换、反渗透处 理, 主要污染物石油类、TDS (总溶解盐) 、TOC、硬度分 别由原来的 $20 \mathrm{mg} / \mathrm{L}, 6000 \mathrm{mg} / \mathrm{L}, 120 \mathrm{mg} / \mathrm{L}$, 和 $5 \mathrm{mg} / \mathrm{L}$ 降到 $0.1 \mathrm{mg} / \mathrm{L}, 145 \mathrm{mg} / \mathrm{L}, 2 \mathrm{mg} / \mathrm{L}$, 和 $1 \mathrm{mg} / \mathrm{L}$, 出水达到美国环保局 饮用水标准, 可用于锅炉给水、农业灌溉和饮用水。我国 国家科技部近年来也设立了科技专项, 立题开展研究, 研 究开发了基于纳滤膜技术的油田采出水软化技术, 并且进 一步用反渗透技术处理软化水, 代替清水作为热采锅炉给 水, 提高污水回用效率, 节约清水资源 [21]。

采油废水经过一定程度的脱盐处理, 能用于作物灌溉, 同时不产生土壤积盐问题, 是一种较理想的结果。因此, 外排污水盐含量标准的确定及其对于沿线生态的影响也 是一项重要的研究内容。经过使用含盐水进行农作物灌溉 的试验表明, 当灌溉水的含盐量控制在一定浓度内, 是可 以用于农作物灌溉的。据河北省水利研究所在河北省南皮 县试区的试验, 利用含盐量为 $2 \sim 5 \mathrm{~g} / \mathrm{L}$ 的咸水, 在小麦拔 节后的生长期浇一到两次水, 取得了明显的增产效果, 而 且在一般降雨年份情况下, 观测到 $0 \sim 60$ 厘米土体内未发 生盐分的累计 [22]。这对于油田方面降低废水脱盐的成本 并使之实用化也有一定意义。美国盐土实验室提出的灌溉 水含盐量划分, 当电导率在 $100 \sim 250$ 微西/厘米为低含盐 水, 可用于灌溉各种作物, 一般不需要对土壤进行淋洗, 土 壤无积盐问题; $250 \sim 750$ 微西/厘米为中等含盐水, 在有适 当淋洗措施条件下, 可用为各种作物灌溉; 而750 2250微 
西/厘米为高含盐水, 不能用于灌溉 [23]。以色列在海水淡 化的工业化应用方面处于世界先进行列, 目前的海水淡化 成本为每立方米淡水 0.6 美元, 这种淡水的氯离子含量仅 为 $20 \mathrm{mg} / \mathrm{L}$, 被大量用来稀释苦咸水后, 实际用于农业灌溉 [24]。这为我国今后开展油田含盐废水的处理和利用提供 了一个可借鉴的成功的范例。

\section{3. 关于针对采油废水排放的土壤环境监测}

土壤环境监测是指通过测定影响土壤环境质量因素 的代表值来确定环境质量以及环境的变化趋势。土壤环境 监测起初在我国主要作为农用地监测 $[44,45]$, 用以测定 土壤肥力。近年来随着环境恶化, 人们逐渐意识到生态环 境的重要性, 因此农田土壤污染环境监测成为研究焦点。 伴随人类生活水平提升, 对石油需求量大幅增加, 我们对 土壤环境的监测的方向也提出了新的要求, 其中关于含采
油废水排放的土壤环境监测已经成为一个重要的研究方 向。

从研究方法上来看, 现今的环境监测主要局限于人工 采样和实验室研究 [46]。研究方向单一, 很难做到以点带 面; 研究方法的智能化 (即与计算机模拟技术紧密结合) 尚有待于开展; 研究成果缺乏多样性与广泛性。

土壤环境质量标准 [44] 是以《中华人民共和国环境保 护法》为依据, 制定的土壤中污染物最高容许量的标准, 该标准适用于农田林地等土壤。该标准标准号为 GB15618-1995，颁布于1995年，实施于1996年。该标准于 2008年进行了修订，修订后的适用范围为农业、居住、商 业以及工业四类用地土壤。除扩大适用范围外，该标准将 污染物种类从 10 项增加至 76 项, 并且增加了有机物质量划 分。

表1我国主要油气田地层水中的含盐成份和矿化度 (表中数字的单位均为 $\mathrm{g} / \mathrm{L}$ )

\begin{tabular}{|c|c|c|c|c|c|c|c|c|c|c|}
\hline 地区/井号 & $\mathrm{Na}^{+}+\mathrm{K}^{+}$ & $\mathrm{Na}^{+}$ & $\mathrm{Ca}^{2+}$ & $\mathrm{Mg}^{2+}$ & $\mathrm{SO}_{4}{ }^{2-}$ & $\mathrm{Cl}^{-}$ & $\mathrm{HCO}_{3}^{-}$ & $\mathrm{Br}^{-}$ & 矿化度 & 参考文献 \\
\hline 塔里木盆地 & $7.82-88.08$ & & 1. $18-24.93$ & $0.09-5.81$ & $0.07-4.7$ & $12.41-14.33$ & $0.03-1.58$ & & $22-320$ & 1 \\
\hline 吐鲁番盆地 & $10-40$ & & $4-4.5$ & $<1$ & $1-2.5$ & $10-78$ & $<1-4.5$ & & $2-120$ & 1 \\
\hline 酒泉盆地 & $5.28-39.17$ & & $0.83-3.57$ & $0.19-0.77$ & $0.19-1.51$ & 7. $77-64.40$ & $0.13-2.01$ & & $6.5^{-70}$ & 1 \\
\hline 松辽盆地 & $0.76-3.18$ & & $0.01-0.07$ & $0-0.03$ & $0.005-0.412$ & $0.64-7.33$ & $0.64-2.99$ & & $0.96-14$ & 1 \\
\hline 黄骅盆地 & $0.37-11.09$ & & $0.01-0.33$ & $0.01-1.19$ & $0.05-0.66$ & $0.21-18.88$ & $0.12-2.21$ & & 1. $30-50$ & 1 \\
\hline 海拉尔盆地 & $0.46-7.20$ & & $0.01-0.07$ & $0-0.05$ & $0.03-0.7$ & $0.08-1.2$ & $0.5^{-16}$ & $0.001-0.004$ & $1.74-25$ & 1 \\
\hline 鄂尔多斯盆地 & $0.13-27.61$ & & $0.08-58.83$ & $0.02-7.83$ & $0-8.66$ & $0.16-162.9$ & $0.09-1.68$ & & $0.93-35.61$ & 2 \\
\hline 鄂尔多斯双南油田 & & 1.80 & $>0.02$ & & 0.6 & 1.6 & 3 & & 7.2 & 3 \\
\hline 内蒙古桑合油田 & & & 0.31 & 0.12 & 0.91 & & & & & 4 \\
\hline $\begin{array}{l}\text { 塔河油田/塔河 } 3.4 \text { 号 } \\
\text { (01) }\end{array}$ & 49.6 & & 18.9 & 2.45 & 0.23 & 111 & 0.26 & 0.36 & $>0.20$ & 5 \\
\hline $\begin{array}{l}\text { 塔河油田/塔河一号 } \\
\text { (T) }\end{array}$ & 69.6 & & 10.8 & 1. 21 & 0.312 & 130 & 0.14 & 0.23 & $>0.20$ & 5 \\
\hline 鄂尔多斯油田/陕52 & 3.76 & & 3. 94 & 0.66 & 0.354 & 14. 20 & 0.40 & $0.0002-1.39$ & 0.02 & 6 \\
\hline 鄂尔多斯油田/陕20 & 2.05 & & 35.57 & 3. 42 & 0 & 103.95 & 0.33 & $0.0002-1.39$ & 0.23 & 6 \\
\hline $\begin{array}{l}\text { 建南气田/建 } \\
44(\mathrm{p} 2 \mathrm{ch})\end{array}$ & & $\begin{array}{l}47.2 \\
0\end{array}$ & 5.48 & 0.63 & 0.40 & 78.4 & 2.1 & & 4.47 & 7 \\
\hline 建南气田/建13 (c) & & 9.00 & 4. 18 & 0.22 & 0.22 & 17.7 & 0.31 & & 1.03 & 7 \\
\hline $\begin{array}{l}\text { 大庆油田/朝阳沟阶 } \\
\text { 地P }\end{array}$ & & 5.23 & 0.05 & 0.02 & 0.17 & 7.33 & 0.96 & 0.001 & 13. 96 & 8 \\
\hline $\begin{array}{l}\text { 大庆油田/朝阳沟阶 } \\
\text { 地F }\end{array}$ & & 1. 67 & 0.29 & 0.03 & 0.51 & 2.24 & 0.84 & 0.004 & 5.73 & 8 \\
\hline 大庆油田/大庆长垣p & & 3. 18 & 0.03 & 0.01 & 0.03 & 3.15 & 2.99 & 0.009 & 9.46 & 8 \\
\hline 大庆油田/大庆长垣Y & & 0.92 & 0.01 & 0 & 0.55 & 0.39 & 0.80 & 0.006 & 2.89 & 8 \\
\hline
\end{tabular}

新西兰先后颁布一系列具有针对性的土壤指导值 SGV, 并且各地区也颁布各自的土壤指导值 SGV。我国的土壤环 境质量标准分为一级标准、二级标准以及三级标准, 分别 以保护区域生态、保护农业生产以及保障农林生产和植物 正常生长为保护目标，其对应的标准值分别是背景值、限 制值以及临界值。目前我国的土壤环境质量标准还存在一 些问题: 首先, 背景值资料不具有代表性，由于我国地大 物博, 地域辽阔, 且各地土壤性质不同; 这些标准值的资 料尚难以反映实际和具体的情况, 且制定的标准值也存在 争议。采油废水在未进行脱盐处理即进行排放将引起排污 渠两侧土壤的次生盐渍化, 给生态环境带来极大威胁, 如 上述报道的大庆油田在早期的油田开发与油气利用过程 中因采油废水排放所导致的周边地质环境遭受了极大的 危害的先例。
由于缺乏含有采油废水土壤的可信度高的数据, 因此 我们所认知的石油开采对于土壤的污染程度以及污染的 持久状态还处于模糊阶段。对于含采油废水的土壤环境监 测尚缺乏足够的关注与完善的评价机制, 因此未经处理的 采油废水直接排放的行为尚未得到及时遏止, 采油废水对 环境的污染日益加重。要解决这个问题就需要各地环保部 门加强油田地区的土壤监测。

含采油废水的土壤监测的重点工作包括: 布点采样、 制样分析以及土壤环境质量评价。布点采样是研究工作的 基础, 布点的方法正确与否、采样的过程是否规范也是研 究成功与否的关键。目前国内外普遍使用的布点方法为: 随机采样法、分区随即采样法、系统网格法 [47]。每种方 法各有利弊, 根据实际研究背景以及研究目的选择布点方 法。采样时最需要注意的问题就是深度, 只有明确土壤样 
品的采集深度, 采取的样品才才具有准确性与代表性。在 土壤环境质量评价方面, 日本规定土壤质量以浸出液浓度 来进行评价。因此只要将浓度与标准值进行对照即可。而 我国目前以总量标准进行评价, 在进行判断时会有一些困 难。

综上所述, 在国际上, 美国、加拿大油田已经进行了 外排废水脱盐处理, 美国盐土实验室已经采用中低浓度盐 水成功地灌溉农作物, 以及以色列对已经海水进行淡化后 用于补充灌溉水。由于我国的环保部门在国家标准中尚未 对外排污水中的矿化度进行规定和限制, 需要通过开展一 系列基础研究, 制定将高含盐采油废水的一部分进行脱盐 处理以降低排水矿化度的标准。随着海水淡化技术的发展 和广泛应用, 已有各种经济实用的脱盐技术和装置可供油 田部门选用于污水脱盐。针对高含盐采油废水排放与沿线 土地的盐渍化问题相结合开展研究工作, 需要开展的研究 和创新之处在于通过对既有的高含盐污水外排过程导致 当地次生盐渍化的程度和机制进行观测分析, 研究污水含 盐量、外排量、渗漏量等控制参数及其对环境的影响, 分 析污水渠道沿线土地盐渍化的时空演变规律, 阐明该类土 壤的盐渍化过程及与油田矿区其它正常土地的异同。需要 基于上述分析数据进行油田矿区水盐运移动力学模拟和 预测, 构建针对油田矿区土壤盐渍化风险控制的污水含盐 排放标准和排放量的环境评价机制, 实现区域土壤盐渍化 风险评价及预警, 为国家环保部门制定污水矿化度标准和 有效防止矿区土壤的次生盐渍化提供科学依据。

\section{4. 关于油田含盐采油废水问题的研究与治理的 展望}

需要以高含盐采油污水外排渠沿线的土地次生盐渍 化问题为研究对象, 通过观测该类渠系对地下水的渗漏和 沿线土地地下水位上升幅度及影响范围, 观测预报渠道沿 线土壤次生盐渍化发生的速度。在掌握区域水盐运动机理 的基础上开展水盐运移和潜水蒸散过程的数值模拟来揭 示区域土壤盐渍化的演变。研究结果可为揭示矿区土壤的 次生盐渍化的时空演变规律和当地环保部门对高含盐采 油废水处理的决策提供理论依据。需要完成以下几个方面 的观测、分析和计算工作:

(1) 排污渠系两侧的土壤次生盐渍化的观测

需观测不同年份、土壤及水文地质条件下渠系外排污 水对地下水的渗漏补给量, 和因之引起的地下水位上升幅 度及影响范围; 定量观测排污渠系两侧的地下水位与矿区 其它正常土地的地下水位的对比, 确定污水渠两侧次生盐 渍化的影响范围; 观测矿区土壤次生盐渍化的时空变异, 对表征土壤盐渍化特征的参数, 如土壤的含盐量、 $\mathrm{pH}$ 值、 有机质、 $\mathrm{Cl}^{-} / \mathrm{SO}_{4}{ }^{2-}$ 等参数进行布点观测; 实地调查、布点 取样观测采集站点附近分层土壤样品的土壤容重、水分特 征曲线、扩散度和导水率等水动力学参数, 观测排污渠沿 线的降雨入渗、土壤水蒸散变化情况, 为探索土壤水盐运 动与转化规律提供依据。

（2）利用经典水盐运移预测模型和软件, 预报矿区预 测年份的排污渠两侧土壤的积盐率分布和盐渍
化范围, 在此基础上绘制矿区的预测年份次生盐 渍化分布图。

（3）以胜利油田现河采油厂外排污水为例, 将结合污 水渠沿线各土地单元内的土地利用方式、土壤质 地、植被条件、地下水埋深和矿化度等，根据土 壤水盐运移数值模型的计算结果, 分析矿区排污 渠沿线土壤次生盐渍化的变化规律, 提出以控制 外排污水的盐含量和地下水水位两个方面的具 体管理措施来防止沿线土壤的次生盐渍化。

(4) 需要以高含盐采油污水外排渠沿线的土地次生 盐渍化问题为研究对象，通过观测该类渠系对地下水的渗 漏和沿线土地地下水位上升幅度及影响范围，观测预报渠 道沿线土壤次生盐渍化发生的速度。在掌握区域水盐运动 机理的基础上开展水盐运移和潜水蒸散过程的数值模拟 来揭示区域土壤盐渍化的演变。研究结果可为揭示矿区土 壤的次生盐渍化的时空演变规律和当地环保部门对高含 盐采油废水处理的决策提供理论依据。为了了解含盐废水 在排放过程中在土壤中的入渗从而导致土壤发生盐渍化 的问题, 需要开展盐在土壤中潜水蒸散的过程数值模拟。 目前常用的软件是Hydrus-1D。

Hydrus $-1 D$ 是可以用来计算在不同边界制约条件下的 水分与盐分运移规律模型的软件。模型可忽略空气对土壤 内的水流运动的影响, 水流状态满足二维或者轴对称三维 的等温饱和一非饱和达西水流条件, 水流控制方程采用的 是考虑作物根系吸水因素的修正Richards对流-弥散方程。 通过对水流区域进行不规则三角形网格剖分, 控制方程采 用有限元法进行求解。

模型有多个详细划分的水流边界模型, 可用以灵活处 理各类水流边界, 可供选择的边界条件分为地面边界和下 端边界, 地面边界类型有: 定压力水头、大气边界产流、 变水头、变水头和通量、定水分通量; 下端边界类型有: 定压力水头、定水分通量、水平排水、自由下渗排水、渗 出面、变流量、变地下水位。水流区域本身可以是不规则 水流边界, 甚至还可以由各向异性的非均质土壤组成。在 软件中有不同的水含量方程、植物根系作用方程、土壤介 质的水力参数的数据库可供选择 [25]。总体来说, 关于盐 水在土壤中的入渗导致盐渍化的过程数值模拟工作需要 进一步开展。

做好本课题的研究需要注意两个关键科学问题:

(1) 高含盐采油废水在流经污水渠的排放过程中, 其 含盐量、排放量与渗透量等参数如何影响两侧土 地的盐渍化过程? 为此需要获得高含盐采油污 水排放渠两侧土地的盐渍化和水盐动力学基本 资料, 在此基础上阐明该类土壤的盐渍化过程及 与油田矿区其它正常土地的异同。

（2）当不同含盐量的采油废水在流经不同地区不同 土质的排放过程中, 我们对废水含盐量、排放量 与渗漏量等参数如何分别进行控制? 依据是什 么? 废水在排放过程中其沿线土地的盐渍化的 时空变异如何? 为此, 需要在获得上述有限的基 本分析数据的基础上, 进行不同的油田矿区水盐 运移动力学模拟。如果仅仅靠实地采样分析, 我 们只能获得非常有限的资料, 特别是不易获得土 
地盐渍化过程的预报资料; 而通过使用计算机开 展数值模拟, 我们可以对矿区的水盐运移进行大 量的计算分析和预测, 从而构建针对油田矿区土 壤盐渍化风险风险评价和控制的污水含盐排放 标准和排放量的环境评价指标体系。

\section{5. 结论}

本文通过总结世界各地油田含盐采油废水的研究现 状, 提出通过布点采样分析, 观测采油污水渠系两侧土地 中因含盐污水渗漏而引起的地下水位上升幅度和范围, 以 及通过实地取样分析获得水动力学参数和土壤盐渍化特 征参数, 利用水盐运移模型预测矿区排污渠两侧土壤的盐 渍化时空变异, 确定高含盐采油污水排放对环境的影响, 针对大型油田排污存在的共性问题, 提出解决该类问题的 完整的技术方案，为矿区污水含盐量控制、地下水位控制 和盐渍化土壤改良提供科学依据。

\section{致谢}

本文为国家自然科学基金面上项目《高含盐采油废水 排放导致土地盐渍化的过程数值模拟研究》 (41471412) 的阶段性成果之一。

\section{参考文献}

［1］霍秋立, 申家年, 付丽, 汪振英, 刘剑营. 海拉尔盆地地层 水特征及成因分析 $[\mathrm{J}]$. 世界地质, 2006, 25卷, 第2期.

［2］李贤庆, 侯读杰, 柳常青, 张爱云. 鄂尔多斯盆地中部气田 奥陶系地层水与水溶气地球化学特征 $[\mathrm{J}]$. 断块油气 田, 2001, 8(3), 1-5.

[3] 黄焕雨. 双南油田储层水水特征分析 [J]. 吉林水利, 2007, (9) , 27-29.

[4] 齐春梅. 新场地区气田水化学特征及处理途径研究 [J]. 成 都理工学院学报, 1999, 26 (2), 168-170.

[5] 周晓芬. 塔里木北部油田水特征离子及其意义 [J]. 石油与 天然气地质, 2000, 21 (4), 372-374.

[6] 徐国盛, 宋焕荣, 周文. 鄂尔多斯盆地中部气田水化学条件 与天然气聚集 $[J]$. 石油实验地质, 2000, 22(4), 330-335.

[7] 潘文蕾, 刘光祥, 吕俊祥. 鄂西渝东区建南气田地层水水化 学特征及其意义 [J]. 石油实验地质, 2003, 25 (3) , 295-299.

[8] 黄福堂. 松辽盆地北部地层水的分类、化学组成与特征研究 [J]. 大庆高等专科学校学报, 1994, 14 (4), 84-100.

[9] 李忠堂, 刘娜, 辛迎春. 王家岗高温污水生物处理中试研究 [J]. 油气田地面工程, 2003, 22（5）, 29-30.

[10] 赵延茂. 吸附法处理现河首站采油污水的研究 [M]. 中国海 洋大学硕士学位论文, 2006.
[11] 汪卫东, 李希明, 蒋沝, 陈勇, 段传慧. 胜利油田污水处理 的主要矛盾及对策 $[M]$. 中国环境科学学会学术年会优秀论 文集，2007，北京.

[12] 王立勇, 董学良, 李楠, 陈兴国. 大庆及周边地区地质环境 问题现状及防治对策 $[\mathrm{J}]$. 黑龙江水利科 技, 2010, 38(1), 177-179.

[13] Seybold A, Cook J, Rajian R V, et al. Demonstration of dissolved organics removal from produced water, SPE. Production Operation Symposium, Okalahoma City: Society of Petroleum Engineers Inc., 1997, 5-8.

[14] 许振良, 膜法水处理技术 [M], 北京: 化学工业出版社, 2001.

[15] 李海波，等.含油废水的膜处理技术 $[J]$. 过滤与分 离, 2000, 10 (4), 10-14.

[16] 耿爱平, 赵江楼, 反渗透技术在脱盐中的应用 $[\mathrm{J}]$. 河南化 工, 1998, 12 (1), 22-24.

[17] Bowman R W, Gramma L C, Craycraft R R, Water softening of high TDS produced water. SPE, International Thermal Operations and Heavy Oil Symposium, Barksfield: Society of Petroleum Engineers Inc. , 1997, 143-154.

[18] Mommaerts G J, Softening of Produced water: which system is best for your application. SPE, International Thermal Operations and Heavy 0il Symposium, Barksfield: Society of Petroleum Engineers Inc., 1999, 1-11.

[19] Doran C F, Carini F H, Fruth D A, et al. Evaluation of technology in treat oil field produced water to drinking water or reusequality. SPE, 1997 Annual Technical Conference and Exhibition, San Antonio: Society of Petroleum Engineers Inc., 1998, 811-822.

[20] Doran C F, Williams K L, Drago J A, et al. Pilot study results to convert oil field produced water to drinking water or reusequality. 1998 Annual Technical Conference and Exhibition, New Orleans: Society of Petroleum Engineers Inc., 1999, 403-417.

[21] 汪卫东, 李希明, 蒋沝, 陈勇, 段传慧, 胜利油田污水处 理的主要矛盾及对策 $[\mathrm{M}]$. 中国环境科学学会学术年会优秀 论文集, 2007, 北京.

[22] US Salinity Laboratory Staff: Diagnosis and Improvement of Salineand Alkali Soils, US Depat. Of Agric. Hanb. 60, 1954.

[23] 河北省水利研究所, 小麦全生长期利用咸水灌溉试验报告 [M]. 见南皮试区综合治理旱涝碱的研究，1981, 84-94.

[24] Tal A, Seeking sustainability: Israel's evolving water management strategy. Science, 2006, 313, 1081-1084.

[25] 尤文瑞, 土壤盐渍化预测预报的研究 [J]. 土壤学进展, 1988, (1) , 1-8. 
[26] 席承藩等译，盐渍土的发生演变 [M]. 北京：科学出版社, 1959.

[27] Kelley W. P., Alkali Soil. New York: Rinhold, 1948

[28] 中国科学院南京土壤研究所主编. 中国土壤 [M], Beijing, 科学出版社, 1978.

[29] 张妙仙, 潜水蒸发规律和调控. 中国水利部水利科技的曙光 [M]. 北京: 北京科学技术出版社, 1997.

[30] 李云祯, 姚远, 庞练, 罗伟, 基于VisualModflow的西南矿 区土壤的地下水重金属污染评价 $[\mathrm{J}]$. 广东农业科学, 2013, (17) ，168-171.

[31] 毛飞, 张桂华，卢志光，金之庆，地下水浅埋条件下冬小 麦和大豆土壤水分动态预报模型研究 $[\mathrm{J}]$. 应用气象学报, 2003，14（4），479-486.

[32] Hu S., Zhao R., Tian C., Empirical models of calculating phreatice vaporating from bare soil in Tarim river basin, Xinjiang. Environmental Earth Sciences, 2009, 59(3), 663-668.

[33] 雷志栋, 杨秀诗, 谢森传, 潜水稳定蒸发的分析与经验公 式 $[J]$. 水利学报, 1984, （8），60-64.

[34] 胡顺军, 田长彦, 宋郁东等, 裸地与柽柳生长条件下潜水 蒸发计算模型 $[J]$. 科学通报, 2006, 50（S1），36-41.

[35] 邵景力, 崔亚莉, 张德强, 基于包气带水分运移模型的黄 河三角洲蒸发量研究 [J]. 地学前沿, 2005, 12, 95-100.

[36] 陈启生, 戚龙溪, 有植被覆盖条件下土壤水盐运动规律研 究 $[J]$. 水利学报, $1996,1,38-45$.

[37] 张妙仙, 毛任钊, 蒸散发条件下农田土壤水盐动态简化模 型 [J]. 中国生态农业学报, 2003, 11（3），102-105.
[38] Zimmerman S., Bauer P., Held R., et al. Salt transport on islands in the Okavango Delta: numerical investigations. Water Resources, 29(1), 11-29.

[39] Nassor I. N., Horton R., Heat, water, and solute transfer in unsaturanted porous media: I-Theory development and transport coefficient evaluation. Transport in Porous Media, 1997, 27:17-38

[40] Hansson K, LundinL C, Equifinality and sensitivity in freezing gandthawing simulations of laboratory and in situ data. Cold Regions Sci. Tech., 2006, 44:20-37.

[41] Kotzer E., Artificial kidneys for the soil: solving the problem of salinization of the soil and underground water. Desalination, 2005, $185(1-3), 71-77$.

[42] 万良兴, 田军仓, 郑艳艳等, 土壤中水、热、盐耦合运移 机理与模型的研究进展 [J]. 节水灌溉, 2007, (3) , 22-25.

[43] 李亮, 史海滨, 贾锦风等, 内蒙古河套灌区荒地水盐运移 规律模拟 [J]. 农业工程学报，2010, 26（1），31-35.

[44] 国家科技保护局科技标准司. 土壤环境质量标准 [Z]. 1995.

[45] 李忠良. 中外土壤环境监测现状及对策建议 $[J]$. 环境经 济, 2005, 03:19-21.

[46] 陈晓冰, 李阳芳. 土壤水分运动方程与参数研究进展 $[\mathrm{J}]$. 现 代农业科技, 2011，(20) :265-268.

[47］彭䈗峻, 袁文芳, 朱艳芳. 生态环境监测的现状及发展趋势 [M]. 江西省宜春市环科所, 2009 (2) : 25-29. 